\title{
Indígenas, africanos y comunidades de fugitivos en la Amazonia colonial ${ }^{\star}$
}

Flávio Gomes ${ }^{\star * *}$

\section{Resumen}

En este artículo analizamos el proceso histórico de la formación de estas comunidades de fugitivos indígenas más allá de las posibilidades del uso de la misma nomenclatura (mocambo) para los esclavos africanos e indios fugitivos. Abordamos los significados de este tipo de protesta (las fugas colectivas y el establecimiento de comunidades) para las poblaciones indígenas en la Amazonia Colonial y la formación de comunidades mestizas de indígenas y africanos, en un proceso de etno-génesis.

Palabras claves: indígenas, negros, Amazonía, fugitivos.

\begin{abstract}
In this article we discuss the historical process of the formation of these indigenous refugees beyond the usability of the same nomenclature (mocambo) for African slaves and runaway Indian communities. We addressed the meaning of this type of protest (collective leakage and the establishment of communities for indigenous peoples in the Amazon Colonial) and the formation of mestizo communities of indigenous peoples and Africans in a process of ethno-Genesis.
\end{abstract}

Key words: indigenous people, blacks, Amazon, fugitive.

En la Amazonia colonial del siglo XVIII había una selva de fugitivos. Las fugas y la formación de comunidades de indígenas fugitivos eran frecuentes y no era raro que lo hicieran con los africanos también refugiados. Esto sucedería en distintas partes de la Capitanía de Grão-Pará, principalmente durante la administración pombalina con la implantación y la posterior desorganización del Directorio de los Indios. Atraían a poblaciones indígenas enteras, "rescatadas", o a través de los "descimentos" acababan siendo reclutadas para el trabajo forzado (Hemming, 1987 y Sweet, 1974). Había una constante migración de las poblaciones indígenas, transferidas de sus lugares de origen a las factorías, fortificaciones y a otras áreas de producción extractiva y agrícola. Este fue un proceso largo y penoso para las poblaciones indígenas amazónicas. Hubo fugas y la formación de mocambos (Coelho, 2007, pp. 29 - 48 y Sampaio, 2007, pp. 39 - 55).

Poco a poco acabaron constituyéndose numerosas comunidades de fugitivos indígenas, comunidades de fugitivos africanos y después comunidades originadas por el mestizaje de los fugitivos africanos e indígenas. Tal vez la administración colo-

\footnotetext{
*Artículo tipo 2, de reflexión según clasificación de Colciencias.

** Profesor del departamento de Historia de la Universidad Federal de Río de Janeiro e investigador del CNPq.

- Nota de la traductora. Durante la colonia, el término "descimento" designaba el traslado hacia el litoral de los indígenas capturados en el interior y a los cuales se esclavizaba.
} 
nial no utilizaba incorrectamente la denominación "mocambos de indios", abundante en la documentación que hemos investigado. El término utilizado para las comunidades de fugitivos africanos que se volvió, junto con quilombo, de uso común gracias a las autoridades coloniales, también era utilizado para definir a los grupos de indígenas que huían y formaban comunidades en la selva. En este artículo analizamos el proceso histórico de la formación de estas comunidades de fugitivos indígenas más allá de las posibilidades del uso de la misma nomenclatura (mocambo) para los esclavos africanos e indios fugitivos. Abordamos los significados de este tipo de protesta (las fugas colectivas y el establecimiento de comunidades) para las poblaciones indígenas en la Amazonia Colonial y la formación de comunidades mestizas de indígenas y africanos, en un proceso de etno-génesis.

\section{Una selva de fugitivos}

Del mismo modo que el proceso de ocupación colonial, las capturas y esclavización de las poblaciones indígenas y la llegada de cautivos africanos a través del tráfico atlántico, las fugas de esclavos e indios reducidos eran un problema crónico desde finales del siglo XVII. En el siglo XVIII hubo un crecimiento de las fugas y principalmente, la formación de comunidades de fugitivos. A mediados de 1752, una diligencia en Cametá fue enviada contra un "mocambo principal" para capturar indígenas que habían escapado. Al año siguiente, en la región más alejada del Tapajós, hubo quejas de los ataques que los indios fugitivos de las reducciones religiosas habían hecho a los campos. Los soldados enviados para destruir este mocambo no tuvieron éxito ya que este contaba "con centinelas a un día de camino antes de que llegaran" y tan solo encontraron "todas las casas desiertas". Los indígenas huían en masa (APEPA, 1752, 1761, 1759). En el río Moju, cerca de Vila de São Miguel e Almas, otra expedición punitiva encontró un mocambo de indios abandonado con "casas y muchos campos de mandioca ". Del Gurupi, las noticias sobre los mocambos contaban que los indígenas "desertan para no trabajar". En Barcelos, en 1761, diligencias contra por lo menos dos mocambos lograron capturar a 30 indígenas. Se descubrió que los fugitivos tenían campos y herramientas en los mocambos. Y se avisaba: "dar en los mocambos me parece muy conveniente, porque es el único medio de restituir los indígenas fugitivos a sus respectivas poblaciones, y al mismo tiempo que consten en ellas los que de ordinario las constituyen, porque los que se encuentran amocambados no perderán la oportunidad de enviar partes para que engrosen su partido" (APEPA, octubre 19 de 1761).

Había mocambos de indígenas por todas partes. En 1762, en Vila do Conde y en Piriá, se decía que existía "ya bastante gente en mocambo" (APEPA, 4 de febrero de 1762). En Portel, había varias denuncias sobre el abandono del "servicio" por parte de los indígenas y de poblaciones indígenas fugitivas "compuestas de mocambos que solamente aparecen cuando quieren". Las investigaciones sobre las fugas colectivas de las reducciones en Soure revelaron "que todos siguen el camino de Arauari, donde se encuentran grandes mocambos". De Vila de Monsarás, cerca del río Caracará, "en las espesuras de Ponte de Pedra se encuentran amocambadas 40 personas de esta aldea entre grandes y pequeños viviendo como en 
el interior sin misa ni confesión ". Thomas Gonçalves, un indio de Vila de Boim llegó a ser acusado, en 1763, de ocultar a "ciertos fugitivos de la misma población, convirtiéndose en cabeza de mocambo" (APEPA, noviembre 24 de 1762 y enero 7 de 1762). No muy lejos del ingenio del Carmelo, se denunció que las expediciones anti-mocambos de indígenas se verían frustradas porque "había una comunicación continua entre algunos indios de estos lugares con los del mocambo, que fácilmente les podrán avisar". En Alter do Chão y en Monte Alegre se realizaron otras diligencias contra los indios fugitivos en 1765. En Serzedelo, en 1791, la atención estaba centrada en los indígenas refugiados que "habían venido a la población, pero escondidos, y con la intención de llevarse a algunas mujeres y amocambarse en la boca de este río". En las aldeas de Francia, Boim, Santarém y Alter do Chão, los colonos y los labradores se quejaban de "los salvajes del monte" en los mocambos que estaban llevando a cabo razias y cometiendo asesinatos. También, en Santarém, en 1773, las noticias informaban que los indios Motrucus estaban amocambados. En el río Arapi se hablaba de los "salvajes en el mocambo" que estaban hambrientos. En Vila de Abaeté, una relación con los nombres de diversos habitantes informaba de la deserción de 20 personas, destacándose entre ellas indígenas y mulatos ${ }^{1}$.

Las rutas de los indios fugitivos podían ser las más diversas. Sus mocambos eran móviles, y podían migrar a otras regiones en distintas direcciones. En Vila de Borba, en 1778, las autoridades fueron alertadas de "prevenir el paso furtivo de los indios de esta Capitanía hacia Mato Grosso". En Benfica, en 1780, intentaron capturar "indios amocambados" en Igarapé Tamatatu y en el río Tanhá. Muchos indios reducidos eran destinados a trabajar muy lejos de las regiones donde se encontraban ubicadas sus aldeas. Esta práctica de las autoridades portuguesas iba también dirigida a dispersar y desarticular a los grupos indígenas. En algunas regiones, el castigo de los indios capturados era enviarlos a otras áreas muy lejanas. En 1781 se ordenaron "copiosas remesas" de indígenas de las Vilas de Ourém, Portel, Melgaço, Monte Alegre, Alenquer y Outeiro a Macapá, como castigo por las deserciones de los viajes del río Negro del servicio de estas aldeas ${ }^{2}$.

\footnotetext{
${ }^{1}$ APEPA, Códice 07 (1752-1769), Oficio de João de Morais Bitencourt, 21/01/1764; Códice 59 (1765), Oficio de João Francisco Furtado de Mendonça, 01/01/1765 y Oficio de Manoel Lobo de Almeida, 12/01/1765; Códice 96 (1769), Oficio de Antônio Albino Machado enviado al Gobierno de Pará, 17/06/1769; Códice 97, Oficio de Belchior Henrique enviado al Gobierno de Pará, 18/10/1769; Códice 09 (1772-1777), Oficio de Manoel Antônio da Costa Sotto-Maior, 24/08/1773; Códice 144 (1774), Oficios de Antônio Gonçalves de Souza, Director del Pesquero Real enviado al Gobierno de Pará, 16 y 17/04/1774 y Códice 150 (1774-1780), Oficio de 22/03/1774; Códice 151 (1775), Oficio de Manoel Marques Mello enviado al Gobierno de Pará, 24/10/1775 y Códice 151 (1775), Oficio de José de Souza Morais enviado al Gobierno de Pará, 09/11/1775 y Oficio de Domingos Gonçalves, Diretor de Pinhel, 08/11/1775.

${ }^{2}$ APEPA, Códice 356, Oficio de José Nápoles enviado al Gobierno de Pará, 05/01/1781; Códice 343, Oficio del Gobernador João Pereira Caldas enviado al Director de Vila de Borba Teniente Francisco Borges dos Santos, 26/02/1778 y Códice 200 (1780), Oficio de Libório Souza enviado al Gobierno de Pará, 16/09/1780.
} 


\section{Cuadro $\mathrm{N}^{\circ}$ 1. Noticias de mocambos de indígenas fugitivos en la Amazonia colonial (1752-1800)}

\begin{tabular}{|c|c|c|c|}
\hline Años & Regiones/áreas & Años & Regiones/áreas \\
\hline 1752 & Río Cupijó & 1768 & Cintra \\
\hline 1753 & Tapajós & 1769 & Serzedelo \\
\hline 1759 & Barcelos & $1769-1773$ & Santarém \\
\hline 1761 & Son Miguel de las almas & 1774 & Umarim \\
\hline 1761 & Barcelos & 1774 & Río dos Arapi \\
\hline 1762 & Amapá/Araguari & 1780 & $\begin{array}{l}\text { Benfica/lgarapé } \\
\text { lamatatua }\end{array}$ \\
\hline 1762 & Mandim & 1780 & Río Tanhá \\
\hline 1762 & Monsarás & 1781 & Portel/Río Arapari \\
\hline 1762 & Río Piriá/Vila de Conde & 1781 & Colares \\
\hline 1762 & Soure & 1782 & Marajó \\
\hline 1763 & Boim & 1783 & Nogueira \\
\hline 1764 & Río Capim & 1785 & Vila de Serpa \\
\hline 1764 & $\begin{array}{l}\text { Cametá/Ingenio del } \\
\text { Carmelo }\end{array}$ & 1787 & Solimões \\
\hline 1765 & Monte Alegre & 1787 & Alenquer \\
\hline 1765 & Alter do Chão & 1789 & Río Bujaru \\
\hline 1767 & Xingu & 1797 & Mondim \\
\hline 1797 & Río Negro & & \\
\hline
\end{tabular}

Fuente: APEPA, códices 7, 8, 9, 24, 25, 26, 27, 39, 45, 59, 77, 88, 96, 97, 114, 144, 150, $190,200,219,227,234,244,246,325$ y 356.

¿Qué sucedía con estas poblaciones indígenas? Hasta mediados del siglo XVIII, el trabajo esclavo en la Capitanía de Grão-Pará se basó fuertemente en la mano de obra indígena, hasta la era pre-pombalina, dividido entre esclavizados e indios. La esclavización se daba por "guerra justa", rescate, "descimentos" y la compra de prisioneros de guerra. También existía la esclavización ilegal llevada a cabo por particulares (Almeida, 1988, pp. 112-114 y Farage, 1991, pp. 31 - 33). En cuanto a los indígenas libres, también estaban divididos en reducciones indígenas organizadas por misioneros. Aparecían reducciones religiosas, reducciones del servicio Real y reducciones de repartición. En Amazonia, las disputas por el control de la mano de obra indígena dominaron este período ${ }^{3}$. Durante la última década del siglo XVII y la primera mitad del siglo XVIII, los conflictos y los desacuerdos entre los jesuitas, los habitantes y los colonos en torno al tratamiento y el control de las poblaciones indígenas reducidas fueron permanentes. Fue el período de las reducciones-misiones. Se realizaron varias entradas y expediciones de rescate para capturar indígenas.

\footnotetext{
${ }^{3}$ Ver: Azevedo, J. L. (1901). Os Jesuítas no Grão-Pará, suas missões e colonização. Borguejo histórico com vários documentos inéditos. Lisboa: Liv. Edit. Tavares Cardoso \& Irmãos; Moreira Neto, C. de A. (1988). Índios da Amazônia, de maioria e minoria (1750-1850). Petrópolis: Ed. Vozes. pp. 21-23.
} 
Las estadísticas sobre el número de indios convertidos por los religiosos son incompletas. Se decía que sólo de indígenas en las reducciones de jesuitas había 11.000 en 1696 y 21.031 en 1730 . En 1750, se calculaba que en todas las órdenes religiosas juntas en la Amazonia (jesuitas, franciscanos, mercedarios y carmelitas) había 63 reducciones y cerca de 50.000 indios reducidos (Belloto, 1988, pp. $55-56)$ y Boxer, 1963, pp. $243-245$ y $251-253$ ). Pero en estas estadísticas de las reducciones no se tuvieron en cuenta las poblaciones indias víctimas de la viruela y de otras epidemias ocurridas allí, así como tampoco la enorme cantidad de indígenas fugitivos. Comentando sobre el impacto de las epidemias en la Amazonia Colonial, Dauril Alden señala que sólo en Belém y sus alrededores, murieron 4.900 personas en 1749 y el año siguiente casi el doble. En el interior, los índices de mortalidad fueron todavía mayores, afectando fundamentalmente a las poblaciones indígenas reducidas o no. En las misiones del río Negro y Solimões más de 2.000 indios murieron. Tan sólo en una misión jesuita, en la desembocadura del río Madeira, hubo 700 muertes. En 1750, la Capitanía de Grão-Pará había confirmado la muerte de más de 18.000 personas y las autoridades preveían que este número podría sobrepasar los 40.000 . El mismo Alden llamó la atención sobre el hecho de que estos cálculos no incluían al gran número de forajidos que formaban mocambos en la selva, cuya presencia preocupaba sobremanera a las autoridades coloniales y metropolitanas, además de a los hacendados (Dauril, 1985, p. 437).

Los jesuitas -además de utilizar a los indígenas como mano de obra esclava en las reducciones- participarían en el tráfico esclavo de indios y después de africanos en Amazonia durante los siglos XVII y XVIII (Sweet, 1978. Pp. 102 - 103). No sólo los religiosos y los colonos, sino también el poder colonial tendría un importante papel en la captura y utilización de la mano de obra indígena. Como bien señaló Monteiro (1994, pp. 111 - 112) sobre la política indigenista colonial en el siglo XVII: "si en las Capitanías del sur, las expediciones fueron emprendidas en rebeldía a las autoridades, la presencia e ingerencia del estado en el abastecimiento y distribución de la mano de obra nativa eran notables" en Amazonia.

Con el proyecto ilustrado pombalino de la región, a principios de la segunda mitad del siglo XVIII, se decretó el fin de la esclavitud indígena y se retiró el poder temporal de los misioneros religiosos sobre las reducciones, destruyendo parte de la estructura de control de la mano de obra en la región. Los conflictos entre el Estado Portugués y los jesuitas por el control de los indígenas reaparecen con más fuerza. El proceso de secularización de las misiones avanzaba y al mismo tiempo el tráfico africano se incrementaba (Salles, 1971, pp. 32 - 33). Este proyecto de desarrollo colonial trae un impacto para la región, produciendo efectos sobre las poblaciones indígenas. Bajo la perspectiva de crear las llamadas "murallas del interior", los indios se transforman en colonos y/o súbditos. Poblaciones indígenas enteras se ven cada vez más atraídas, convirtiéndose las antiguas reducciones en villas. En 1757, el entonces Gobernador Mendonça Furtado creó los Directorios pombalinos. En la perspectiva del control de la población indígena, consistiría en un conjunto de medidas que regían la vida. Se incentivaría la agricultura, surgiría la figura del director de las villas que mediaría en las actividades económicas. 
Además del desarrollo económico de la región, este conjunto de medidas iba dirigido tanto a controlar a los indios como a aplacar la ira de los colonos, insatisfechos con el problema de la mano de obra. Se temían los motines de los habitantes y los colonos y la dispersión de los indígenas esclavizados y reducidos (Farage, 1991, pp. 48-50).

Según Mclachlan, la Corona portuguesa implementó, de hecho, un tipo de control agresivo sobre el trabajo indígena a lo largo del siglo XVIII, principalmente después de extinguir el sistema de las misiones (1973, pp. 228-230). Los Directorios se crearon en mayo de 1757, y fueron confirmados en agosto de 1758. Antes -- en junio de 1755 - se decretó una ley que liberaba a los indígenas de la Capitanía de Graõ-Pará. Sólo en mayo de 1758, es decir, tres años más tarde, esta ley se extendería a las demás Capitanías. Para Belloto (p. 59), la "intención del Directorio iba mucho más en el sentido de apartar a la Compañía de Jesús que no a disminuir la sujeción de los nativos al trabajo forzado". Pero la creación de los Directorios formaba parte de una política colonial, al mismo tiempo de control de la mano de obra indígena y de ocupación de Amazonia. La inclusión sistemática, por ejemplo, de personas "blancas" en las reducciones tenía una perspectiva de integración, dominio y ocupación (Perrone-Moisés, 1991, pp. 115-132). Entre las principales imposiciones de los Directorios estaban: a) la lengua general; b) las escuelas y profesores; c) el estilo de ropa; d) la vida familiar; y e) la integración económica y política. Como parte del control también se pagaba el diezmo (MacLachlan, 1972, pp. 363-365).

En las mentes de las autoridades coloniales este era un período de transición. Los indios podrían continuar siendo utilizados en el cultivo de la tierra, sin embargo, los habitantes tenían que pedir permiso a través del Tribunal de Huérfanos. Bajo el punto de vista de la "moralidad" y la "civilización" se articularía la obligación al trabajo y la disciplina de la mano de obra. Los Directorios se extinguirían definitivamente en 1798 (Farage, 1991, p. 52). Aunque ya se daban antes, las fugas de los indios y la formación de mocambos - en este contexto de transformación de las prácticas y expectativas coloniales - aumentaron bastante. Refiriéndose a la fuga, algunos meses antes del decreto de abolición de la esclavitud indígena, alguien dirían: "no hay modo de hacerlos parar [de huir], porque en las reducciones no sólo no son castigados sino, al contrario, son favorecidos y amparados, y sin estos indios ya Vuestra Excelencia sabe que no se puede hacer nada (Mendonça, 1967, PP. 554 -555). Con la desorganización de las misiones y la creación de estos Directorios, además de aumentar en frecuencia, las fugas pasaron a ser en masa.

Las poblaciones indígenas percibían las políticas coloniales en Amazonia y las disputas locales e internacionales en torno a ellas. En otros contextos coloniales, los grupos indígenas, los esclavos africanos, los ejércitos coloniales, los colonos, los marineros, los piratas y las autoridades tuvieron percepciones del complejo proceso de ocupación colonial que implicaba guerras, tráficos, esclavización, etc. En la Amazonia, teniendo en cuenta la tradición de resistencia indígena a lo largo de la colonización, tal vez podamos analizar las fugas de los indios y la formación de comunidades como readaptaciones de significados indígenas y africanos. Cra- 
ton (1986, pp. 96-97 y 108-109), usando la idea de "continuidades" aborda las posibles semejanzas estructurales en los modelos de opresión y resistencia y las conexiones de significados en las transformaciones de resistencias de los Caribs y de los Blacks Caribs en el Caribe. Los indígenas comenzaron a ver a los africanos como aliados circunstanciales y en algunos momentos fueron animados a huir. Además, las distintas poblaciones indígenas locales - principalmente los Caribs se dieron cuenta y utilizaron a su favor las divisiones, los conflictos y las guerras entre los colonizadores europeos desde el siglo XVIII. Esto sucedería en otras áreas esclavistas de las Américas.

En la Amazonia Colonial sucedían procesos históricos de resistencia y significados políticos semejantes. Desde el siglo XVII, las poblaciones indígenas venían conociendo las políticas coloniales de rescate, entradas, "descimentos" y reducciones. Hasta la primera mitad del siglo XVIII, observarían los conflictos entre los colonos, las autoridades y los jesuitas en torno a las misiones. La resistencia a las misiones ya se daba con fugas colectivas y también con razias. Al mismo tiempo, los grupos indígenas que no habían realizado "descimentos" y/o que fueron efectivamente reducidos acabaron migrando. Las experiencias seculares de migraciones de grupos indígenas ahora se daban en un contexto de ocupaciones de fronteras, disputas e implementación de políticas coloniales en Amazonia, además del recrudecimiento del tráfico atlántico de africanos (MacLachlan, 1972, pp. 380). Varios estudios han demostrado cómo las poblaciones indígenas seguían con expectativas las transformaciones de las políticas indigenistas coloniales ocurridas en el siglo XVIII, principalmente con la ley de la emancipación y la creación y reglamentación de los Directorios (Servlnikov, 1996, pp. 211-212).

Por otra parte, los indígenas no reducidos pueden haber provocado nuevos procesos migratorios, incluso traspasando fronteras en disputa. En las villas formadas por los Directorios - con numerosos indios reducidos - se darían cada vez más fugas colectivas y la formación de mocambos a partir de ellas. Cabe destacar que hubo en los Directorios intentos de unir grupos étnicos indígenas rivales. Y como ya dijimos, en los "descimentos" las poblaciones indígenas de algunas áreas eran transferidas a otras más lejanas. En este en caso, los grupos indígenas fueron divididos y distribuidos en varias reducciones. Con las fugas colectivas y la formación de "mocambos de indios" de las que tanto se habían quejado las autoridades coloniales en la Amazonia Colonial, los indígenas refugiados deben haber intentado -motivados por dinámicas propias o frente a la imposibilidad de volver a las regiones de origen de sus tribus- establecerse en comunidades en la selva, reorganizándose en nuevos grupos étnicos y socio-económicos. Así, podemos reflexionar sobre los significados de etnogénesis en la formación de los mocambos de indios y de las fugas colectivas en el contexto 1755 a 1790, cuando desaparecieron las misiones y se crearon los Directorios (conflictos étnicos con los "principales" de las reducciones) y los distintos cambios en la legislación (Coelho,2007, pp. 29-48 y Sampaio, 2007, pp. 39-55). 


\section{Indígenas y africanos en los mocambos}

Las estrategias de los indígenas y los africanos en los mocambos podían tener conexiones. Así lo percibieron las autoridades coloniales y metropolitanas. Quizás esto explica la serie de consultas que las autoridades coloniales le hicieron al Consejo de Ultramar. En 1752, el gobernador Mendonça Furtado le envió una carta al rey, donde de nuevo le pedía que las penas previstas para los africanos por la ley de 1741 también se aplicaran a los indígenas amocambados de la Capitanía de Graõ-Pará. Apoyaba su argumento diciendo que, a pesar de que una consulta al Consejo de Ultramar sobre este tema no había sido atendida, los habitantes de Pará tenían la costumbre de marcar con un hierro su nombre en el pecho de los indios que habían huido de su poder (Mendonça, 1967, p. 304). Mientras los burócratas coloniales no inventaron nombres para clasificar la formación de las comunidades de fugitivos indígenas, los habitantes y las autoridades de Graõ-Pará crearon prácticas específicas para la represión de los indios que huían.

Entre las áreas donde aparecieron los "mocambos de indios" se distinguen justamente las regiones de Alter do Chão, Melgaço, Nogueira, Santarém, Boim, Barcelos, Serpa, Colares, Portel, etc. En estas regiones se establecieron las principales villas y Directorios pombalinos en la década de 1750 (reis, 1966, p. 135). Aquí, huir y establecer mocambos podía significar resistir a las imposiciones de las reducciones. En la década de 1780 las fugas de indígenas aumentaron, por lo menos en las regiones de Nogueira, Colares, Soure, Barcelos, Melgaço, Joanes, Ourém, Monte Alegre, Cintra, Alenquer y Río Negro, entre otras. No fue por casualidad. En este contexto había aumentado la retención de los indígenas, y se permitían el reasentamiento privado y los "descimentos". Por otra parte, también había una excesiva demanda de mano de obra del Estado. Cada vez más, necesitaban brazos para la construcción y la provisión de las fortalezas, el mantenimiento de los caminos y puentes, las canoas de vigilancia, etc. Igualmente aumentaban los trabajos en las expediciones demarcatorias (Almeida, 1988, pp. 114-116 y Farage, 1991 , p. 53). Aunque en 1755 , la Corona Portuguesa determinara para los indígenas de las Capitanías de Graõ-Pará y Maranhão "la libertad de sus personas, bienes y comercio sin otra inspección temporal que no fuese la que deben tener como vasallos", siguieron utilizándolos en el trabajo forzado. En 1775, en Baião, los indígenas eran denunciados "porque no querían trabajar de ninguna manera y con sus fugas habían causado muchos perjuicios" a las canoas de negocio. Todavía en 1803, había quejas contra Conde dos Arcos porque allí como en otras Capitanías existía la "abusadora costumbre" de obligar a trabajar a los indígenas por un "tenue jornal". Por eso eran corrientes las fugas de los esclavos, "buscando unos otras Capitanías y otros las tierras del interior y la selva"4.

A pesar de la extinción del Directorio y de toda la legislación sobre la libertad de los esclavos, la explotación del trabajo forzado indígena nunca cesó en Amazonia. Como señaló Nádia Farage (1991, p. 47), la libertad de los indígenas era una fic-

\footnotetext{
${ }^{4}$ APEPA, Códice 151 (1775), Ofício de Boaventura da Cunha Caldeira, Director de Fragoso, enviado al Gobernador João Pereira Caldas, 24/09/1775 y Códice 606, Oficio de 18/08/1803.
} 
ción política. En 1790, fue encarcelado Miguel de Carvalho acusado de contratar, sin títulos, a un "gran número de indios "para sus campos. Al mismo tiempo, había falta de control y las autoridades portuguesas se hacían las de la vista gorda. Los mismos colonos se quejaban de la escasez de mano de obra para los cultivos y la producción extractiva. A su vez, las autoridades de Pará sabían la vital necesidad que tenían las haciendas reales del trabajo indígena, la tripulación de las canoas, etc. Con la falta de géneros en la región se intentaba sin éxito "promover los cultivos particulares de los indios a través de la persuasión".

Mientras tanto, la población indígena disminuía. Por si fueran pocas las deserciones, también tenían el problema de las epidemias. Con la continuidad de las fugas, los indígenas no sólo se dieron cuenta del impacto de las enfermedades, sino también de los cambios en la política colonial. Una visita pastoral a la región del río Negro, en 1762, denunció que los indios Ariquena habían huido en masa, "muchos de nuestras tierras hacia los castellanos" (Queiroz, 1961, p. 252). Todavía en 1780 , se notificaba que indios esclavizados "por no querer servir a sus señores se habían amocambado en las cabeceras de este río [São Bento] y con la noticia que tuvieron de la ley de las libertades, fueron voluntariamente descidos", habiéndoles cedido la Corona tierras para que produjeran. También en este momento, las autoridades y los colonos intentaron establecer el tráfico de africanos hacia Amazonia de forma más eficaz ${ }^{5}$. Sin duda, los indígenas también, tuvieron una percepción de la selva cada vez más negra con la llegada de los africanos.

Al mismo tiempo que aumentaban los descimentos de grupos indígenas se multiplicaban los mocambos (Perrone-Moisés, 1991, p. 18). De la villa de Portel, en 1781, se enviaban tanto diligencias para seguir el descimento de los indígenas del Pacajaz como para destruir un mocambo en el río Arapari. En el río Taqueri, en la isla del Marajó, se decía que "junto a la hacienda de Angélica de Barros hay un mocambo". En Santarém, en el área de Tabatinga y en otros lugares definidos por los tratados como fronteras con los dominios españoles también se notificaba la existencia de numerosos mocambos. En los lagos del Capim Tuba y Paracari, en Alenquer, fueron apresados 25 indios amocambados. En 1789, fue enviada una diligencia al Bujaru, al lado del río Jabutiapepú, para prender a fugitivos indígenas. A menudo, se temía que los indios amocambados atacaran las villas. La deserción de los indígenas -bien sea por la frecuencia o la cantidad- acabó desorganizando parte de la economía extractiva en Graõ-Pará, tanto la de los colonos como la de las haciendas y propiedades de la corona ${ }^{6}$.

\footnotetext{
${ }^{5}$ APEPA, Códice 456, Oficio de 18/01/1790; Códice 551, Oficio de 08/08/1798 y Códice 200 (1780), Oficio de $10 / 02 / 1780$.

${ }^{6}$ APEPA, Códice 356, Oficio de 22/06/1781; Códice 190 (1782), Ofício de 19/06/1782; Códice 244 (1787), Ofício de Luiz da Rocha Lima al Gobierno de Pará, 28/11/1787 y Códice 246 (1787-1793), Ofício de Hilário de Moraes Bitancourt enviado al Gobernador Martinho de Souza Albuquerque, 01/09/1789.
} 
Cuadro $\mathrm{N}^{\circ}$ 2. Noticias de mocambos formó por africanos e indígenas en la Amazonia Colonial (1762-1791)

\begin{tabular}{|l|l|l|l|}
\hline \multicolumn{1}{|c|}{ Años } & Regiones/áreas & \multicolumn{1}{c|}{ Años } & \multicolumn{1}{c|}{ Regiones/áreas } \\
\hline 1762 & Melgaço & 1774 & $\begin{array}{l}\text { Amapá/Río Anaurap- } \\
\text { cu }\end{array}$ \\
\hline 1767 & Portel & 1774 & Baião \\
\hline 1767 & Melgaço & $1774-5$ & Amapá/Río Matapi \\
\hline 1769 & Xingu & 1775 & Río Monsarás \\
\hline 1769 & Outeiro & 1775 & Benfica \\
\hline 1772 & $\begin{array}{l}\text { Ponta de Pe- } \\
\text { dras }\end{array}$ & 1789 & Cametá \\
\hline 1774 & Salvaterra & 1791 & Almerim \\
\hline
\end{tabular}

Fuente: APEPA, códices 26, 83, 93, 112, 124, 146, 150, 151, 153, 255, 262 y 266.

Además, para analizar mejor las estrategias de la población indígena en diversas áreas de la extensa Amazonia Colonial sería importante rescatar y seguir la etnohistoria de determinados grupos indígenas. En el área del Solimões, por ejemplo, desde finales del siglo XVIII, existía un comercio ínter tribal intenso. Hubo contactos con las misiones españolas y también con los colonos europeos (incluso holandeses) en la región de la frontera con la Guayana Inglesa. Otro factor importante fueron las migraciones constantes de algunos grupos indígenas. Existía, incluso, una tradición india de migración y movilidad. En el área del Tapajós igualmente donde hubo una ocupación colonial- esta tradición puede, por ejemplo, ayudar a explicar los significados de la resistencia y las fugas indígenas, especialmente a partir de la reconstrucción etno-histórica de los procesos migratorios y de los contactos interétnicos de los indios Munduruku (Menendez, 1983, pp. 2734). El incremento de las fugas y de los mocambos indígenas en Graõ-Pará también se daban cuando desembarcaban allí africanos en mayor cantidad. Sería posible sugerir que la tradición indígena de las fugas en seguida se inspiraría en las realizadas por los africanos en algunas áreas. Éstos y sus descendientes, con la ayuda y junto a los indígenas, crearon sus rutas de fuga, mocambos y buscaban la autonomía en medio de la selva.

En 1752, en una pequeña granja de Antônio Nunes da Silva, en el río Cupijó, se decía que existían indios escondidos con criminales y africanos. Diez años más tarde, acusaron a los africanos y a los indios en Beja de hacer "salga" juntos. En la misma ocasión, fueron capturados negros, mulatos e indios en un mocambo, en la región de Melgaço, en el Tapajós. En 1772, en Ponta da Pedra, se intentaba destruir "un mocambo de indios, mulatos y criminales, cuya cabeza es un mulato llamado Narciso que fue de los padres de la Compañía". Estos fugitivos practicaban robos y comerciaban con las poblaciones cercanas. Las solidaridades entre los indígenas y los africanos y sus descendientes en esa tierra común que los esclavizaba comenzaban a aparecer. Los indios en Salvaterra invadieron la cárcel

\footnotetext{
- Nota de la traductora: La "salga" era un hechizo que se le practicaba a alguien esparciendo sal en la puerta de su casa.
} 
para que el "negro Manoel Jose" se diera a la fuga. En la región de Macapá, indígenas de la "nación Marauanu" estaban refugiados con los africanos. También de Gurupá se notificaba que indios y zambos fugitivos andaban juntos. En la región de Baião, el mameluco Francisco Gregorio mantuvo contactos con el "salvaje Arámary" en la catarata del río Itá-quona. En Joanes y Monsarás, fue apresado el negro fugitivo Miguel, conocido ladrón de ganado, a través de quien se supo que los indígenas locales "tenían comercio con los dichos fugitivos". En Benfica, aún en 1775, a propósito de una expedición contra "un mocambo de indios vagabundos", sucedió que: “(...) viniendo los indios que los conducían a este lugar se encontraron con los negros de Francisco Antonio, y como dichos vagabundos tenían contactos con los negros, éstos les quitaron los presos de las manos a los indios de la población"

Los mocambos de los indios y los africanos y sus descendientes se mezclaban. Las autoridades buscaban uno, encontraban otro, o ambos. En 1790, en los montes del ingenio de un capitán, en el río Acará, ocurrieron dos muertes. Con la recomendación de "todo el secreto", se decidieron las investigaciones, cuyo objetivo era descubrir si "por allí o por otros caseríos pequeños, habrá mocambos de negros o indios fugitivos". En 1795, se enviaron de Cachoeira dos escoltas, una "por los ríos de Anavejú, Tauhá, Atujá, y la otra por la desembocadura del río Atuá, por todas aquellas islas adyacentes, Muaná, Pracaúba para impedir las absolutas (sic) [¿absurdos?] que los indios, negros y soldados desertores suelen hacer por aquellas partes". En Almerim, los mulatos y los indígenas fugitivos que andaban por la selva fueron acusados de incendiar una residencia. También en la frontera con la Capitanía de Goiás denunciaban que los africanos e indios fugitivos podrían aliarse con el objetivo de robar el oro ${ }^{1}$. Cerca del río de los Macacus, junto a las cabeceras del río Mapirá, a principios del siglo XIX, fueron capturados fugitivos africanos e indígenas. Las investigaciones hechas entre algunos de los capturados y otras personas llevaron a descubrir que existía: "en el centro de la espesura de la Isla de Joannes muchos mocambos con mucha gente y muy diferente escondida por algunas personas graduadas de estos mismos distritos que los sacaban de

\footnotetext{
${ }^{7}$ APEPA, Códice 08 (1752-1773), Ofício de José Fernando Neves enviado a Manoel de Souza Coelho, 09/07/1752; Códice 25 (1762), Ofício de 10/05/1762; Códice 26 (1762), Ofício de 24/11/1762 - ver también: Ofícios de 14 y 17/11/1762; Códice 124 (1772), Ofício de Manoel de Gusmão enviado al Gobernador, 21/06/1772; Códice 146 (1774), Ofício de Francisco Luiz Ameno, 22/01/1774; Códice 143 (1774), Ofício de Manoel da Gama Lobo de Almeida enviado al Gobernador João Pereira Caldas, 01/10/1774; Códice 146 (1774), Ofício de Antônio José Pinto enviado al Gobernador João Pereira Caldas, 24/01/1774; Códice 151 (1775), Ofício del Director de Baião João Marçal enviado al Gobierno de Pará, 23/10/1775 y Códice 112 (1770-1775), Ofícios de Florentino da Silveira Frade enviado al Gobernador João Pereira Caldas, 11 y 27/02/1775.

${ }_{8}^{8}$ APEPA, Códice 153 (1775), Ofício del Director de Benfica Antônio Gonçalves Ledo, 31/01/1775.

${ }^{1}$ APEPA, Códice 466, Ofício del Gobernador Don Francisco de Souza Coutinho enviado al Capitán Narcizo Maciel Parente, 14/09/1790; Códice 290 (1795-1796), Ofício de Florentino da Silveira Frade enviado a Don Francisco de Souza Coutinho, 29/09/1795; Códice 262 (1790-1799), Ofício de João Garcia Galvão de Maio Farinha enviado al Gobierno, 02/04/1797 y Códice 614 (1795-1797), Ofício del Gobernador D. Francisco de Souza Coutinho enviado al Alferez Joaquim José Máximo, 12/06/1797.
} 
sus trabajos y negociaciones, como sucedía con estos que fueron aprehendidos, que se comunicaban con ellos bastantes personas, sirviéndose de su trabajo"2.

\section{Identidades y comunidades}

A diferencia de los españoles y portugueses que intentaban imponer su soberanía, "civilizar" y cristianizar a los grupos indígenas, los holandeses tenían una relación fundamentalmente mercantil con las poblaciones indígenas. En la Guayana Holandesa - más tarde Surinam- varios grupos indígenas, en los siglos XVII y XVIII, servían de intermediarios, incluso en el tráfico de esclavos indios. También utilizaban grupos indígenas como milicias para combatir las fugas y las rebeliones de esclavos negros (maroons). Los indígenas Karinya tenían una lengua considerada "lengua franca", lengua de trueque e intercambio, comprendida por los Tupi del Oiapoque. También es de destacar, que los vendedores itinerantes holandeses que cruzaban toda la región de la Guayana Occidental, guiados por indios, eran invariablemente africanos y mestizos, y hablaban, por lo menos, una lengua indígena. Hablando sobre los Blacks Caribs, Dreyfus señaló: "Mestizos de Kalinopam (Garifunas) y de Negros Maroons, los Blacks Caribs, fueron deportados por los ingleses en 1797, de la isla de St. Vicent a la Honduras Británica (actualmente Belice), donde se establecieron definitivamente. Ellos han conservado la lengua Aruaque de los Kalinopam, cuya auto-denominación conservó igualmente: Garifuna" (Dreyfus, 1993, pp. 19-41).

La cuestión de la lengua fue un factor importante en la colonización de la Amazonia. Al principio, los grupos indígenas sólo podían comunicarse con los religiosos en las misiones y después con los traficantes y los colonos en las fronteras. Las "lenguas" se podían crear tan sólo a efectos del comercio, uniendo diferentes grupos indígenas y diversos colonos extranjeros. Inicialmente, la idea de crear una "lengua general" en los Directorios pombalinos debe haber fracasado en el sentido de hacer desaparecer las distintas "lenguas" indígenas. Todavía en 1759, el gobernador enviado por Pombal a Graõ-Pará, Mendonça Furtado, con aires de sorpresa destacó que había visto a niños indios hablando parcialmente portugués, ya que "hablando yo con ellos, que entendiendo poco portugués, comprendían y explicaban bastante en la lengua de Tapuia, o llamada general". Y más todavía fue haber visto "dos negros de los que recientemente se están introduciendo de la Costa de África, hablando con desenvoltura la susodicha lengua, y sin comprender nada de la portuguesa" (Reis, 1966, p. 189). Se puede suponer que la diferencia de la "lengua" no constituía un problema, ni una frontera entre los indígenas, los africanos y otros sectores de la sociedad envueltos en el proceso de colonización de la Amazonia en el XVIII.

En las fronteras de la Guayana Francesa, el gobernador Souza Coutinho estaba preocupado por las conexiones entre los indios y los africanos que no sólo tenían "parientes" del otro lado de la frontera, sino que todos hablaban la "lengua gene-

\footnotetext{
${ }^{2}$ APEPA, Códice 324, Ofício de Joaquim Manoel Pereira Pinto enviado al Gobernador Don Francisco de Souza Coutinho, 09/08/1801.
} 
ral”3. En 1753, en una carta real al gobernador de la Capitanía de Pará se recordaba la necesidad de formar reducciones en las orillas del Río Branco y enviar patrullas contra las incursiones de los holandeses para rescatar esclavos indígenas. Dos años después, señalando la importancia de la nueva Capitanía de São José do Rio Negro se hablaba no sólo de vigilar a los holandeses, sino a los indios Caribs, que atacaban en las fronteras. El mismo Alexander Rodrigues Ferreira relata que los indios del lado de Brasil intentaban prender "negros holandeses" cerca de la frontera. Se sabía "que en los distritos donde estaban, andaban negros holandeses seguidos por indios Caripunas, capturando a los salvajes y ejerciendo sobre ellos todo tipo de hostilidades". Intentaron capturarlos, "sin embargo, en lo que tengan noticias de la escolta, tratarán de retirarse a sus dominios"4.

Grupos indígenas, esclavos, africanos, indios fugitivos, traficantes y colonos estaban marcando las fronteras coloniales con experiencias históricas. Pero no todo era armonía, ya que las alianzas y las hostilidades podían ser más circunstanciales que duraderas. Al igual que en otras áreas de Brasil y en el resto de las Américas, las relaciones entre los indios y los africanos también estuvieron marcadas por los conflictos. En Graõ-Pará no fue diferente. Y sucedió en diferentes áreas. En Joanes, en 1762, en una ocasión los negros intimidaron a indígenas desertores. Muy lejos de allí, en el río Xingu, un indio cayó preso por haber agredido a un mulato. En Penha Longa, se cometió incluso un asesinato: el indio Joaquín mató a un mameluco, habitante del río Obituba. En Benfica, algunos negros fueron acusados de atacar a indígenas locales. Años más tarde, del otro lado de la Capitanía, en Santarém, la casa de un indio fue invadida de noche por negros que "robaban y desordenaban". La víctima recibió "muchos golpes"

Esta no era la única situación que se presentaba, ya que no era raro que las tropas que entraban en las espesuras para capturar a los fugitivos africanos y destruir sus mocambos estuvieron formadas por indios y/o guiadas por ellos. En Ourém, en 1762, las autoridades mandaron a destruir un mocambo de cautivos y africanos, pero tuvieron que aguardar a los indígenas porque "estaban plantando en sus campos" y "que acabando de plantar" mandarían "hacer la diligencia a dicho mocambo". Para perseguir y detener a más de 50 fugitivos africanos de la obra de fortificación de Macapá se expidió una fuerza formada por indios y negros ladinos. En Porto do Moz, también se utilizaron indios para combatir los mocambos. De la región del Turiaçu, en el límite con la Capitanía de Maranhão, en 1771 y de nuevo en 1774, las tropas indígenas capturaron a negros fugitivos. En la región de Pesqueiro, en el río Araguari, los indios de la población del Ananim "dieron con el mocambo de los negros fugitivos de Macapá, aprisionaron a veinte, mataron a siete y la mayoría huyó". En Santarém, en los últimos años del siglo XVIII, para

\footnotetext{
${ }_{3}^{3}$ APEPA, Códice 552, Oficio de 20/04/1798.

${ }^{4}$ APEPA, Códice 552, Oficio de 20/04/1798.

${ }^{5}$ APEPA, Códice 27 (1762), Ofício de André Corsino Monteiro, 23/07/1762; APEPA, Códice 93 (1769), Ofício de Joel Caetano Ferreira da Silva enviado al Gobernador Fernando da Costa Ataíde Freire, 20/08/1769; Códice 103 (1770), Ofício de José Manoel Machado al Gobernador, 08/01/1770; Códice 153 (1775), Ofício de Antônio Gonçalves Ledo, 31/01/1775 y Códice 339, Ofício de João Bernardes Borralho enviado al Conde de Arcos, 29/01/1805.
} 
atacar los mocambos de fugitivos se preparaba "un destacamento de tropa competente a la que deberán unirse los de milicianos e indígenas que fueran numerosos por esos parajes"6.

En general, mucho antes que los africanos, los indios integraban las milicias coloniales. En 1778, en la región de Joanes se ordenó la formación de una compañía de infantería con indios y mestizos. En 1797 y 1799 se ejecutaron otras órdenes en este sentido ${ }^{7}$. Es evidente que parte de estas divisiones, no sólo entre indígenas, sino también criollos, africanos e indios de grupos étnicos diferentes eran provocadas por las autoridades coloniales. Formaba parte de las estrategias de dominación y era fundamental en aquella caldera étnica de Graõ-Pará. También en la correspondencia de Alexander Rodrigues Ferreira aparecía anotada la perspectiva de hacer una política de alianza y atracción de algunos grupos indígenas, no sólo con los reducidos y/o con los que se hubiesen hecho descimentos (Farage y Amosoro, 1994, p. 117). Es bueno destacar que si los esclavos africanos tenían culturas e historias distintas, los indígenas de Amazonia no eran diferentes. Lo que en realidad llamamos generalizadamente indígenas, aquí constituían grupos étnicos y lingüísticos diversos, muchas veces rivales. En ese momento, fue un verdadero mosaico de poblaciones las que vivieron en la Amazonia, junto con los africanos y los europeos. En la región del Jamari, el área del Amapá, 1799, los indios Maués, además de huir de las persecuciones de las "tropas de blancos" temían los ataques, tanto de los Mundurukus como de los Caripunas ${ }^{8}$. El año anterior, preocupada por los mocambos de africanos en el Amapá, una autoridad escribiría: “(...) Ordené intentar el expediente de atraer un cuerpo de seiscientos a setecientos indios de la nación Mundurukus (la más guerrera de esta Capitanía, y que últimamente se logró reducir a la paz como le dije a Su Excelencia en su momento) por entender, que sería la gente más apropiada para guerrear contra negros entre selvas y pantanos"?.

Éstos y otros factores provocaron conflictos y animosidades entre los africanos y los indígenas fugitivos. En Benfica, en 1775, donde ya hemos señalado que los indios "vagabundos tenían contactos con los negros", los indios de las poblaciones acusaban a éstos últimos de "ataques", pues "siempre que los indios van a pescar a la orilla de su riachuelo, les quitan las canoas, y los aparejos, y les dan muchos golpes, y así están los indios de intimidados, que mueren de hambre por el temor

\footnotetext{
${ }^{6}$ APEPA, Códice 24 (1762), Ofício de Belchior Henrique enviado al Gobernador, 01/03/1762; Códice 61 (1765), Ofícios de Nuno da Cunha de Ataíde Verona enviados al Gobernador, 03 y 23/08/1765; Códice 165, Ofício de João Amorim Pereira enviado al Gobernador Fernando da Costa de Atayde Freire, 26/12/1766; Códice 589 (1751-1773), Ofício enviado al Gobernador João Pereira Caldas, 26/05/1771 y Códice 140 (1774), Ofícios de Joaquim de Mello e Povoa enviados al Gobernador João Pereira Caldas, 04/05 y 28/09/1774; Códice 279 (1793-1799), Ofício de Manoel Joaquim de Abreu enviado al Gobernador Don Francisco de Souza Coutinho, 29/07/1792 y Códice 554, Ofício del Gobernador Don Francisco de Souza Coutinho enviado al Capitán Comandante de Santarém, 03/12/1799.

${ }^{7}$ Ver: APEPA, Códice 322, Ofício del Consejo de Ultramar enviado al Gobernador João Pereira Caldas, 15/10/1778 y Códice 549, Ofício de 09/06/1797; Ofício de 29/01/1799 y Ofício de 03/09/1799.

${ }^{8}$ APEPA, Códice 311 (1799-1800), Ofício de Luiz Pinto Cerqueira enviado al Gobernador D. Francisco de Souza Coutinho, 20/11/1799.

${ }^{9}$ APEPA, Códice 552 (1798), Ofício enviado al Gobernador D. Rodrigo de Souza Coutinho, 29/03/1798.
} 
que les tienen a los negros" ${ }^{\prime 10}$. De Santarém, enviaron un preso encadenado, el zambo Benedito, debido a los disturbios que hacía con los habitantes indígenas. Los conflictos y las solidaridades también podían surgir con los colonos "blancos". En Vila de Serpa, en 1785, un sargento fue acusado por proteger a indígenas fugitivos e incluso porque existía un mocambo en el interior de su hacienda ${ }^{11}$.

\section{Consideraciones finales}

En Amazonia, el proceso de ocupación fue muy complejo por tratarse de un área de varias fronteras internacionales. Hubo distintos tipos de estrategias coloniales de ocupación, que involucró indígenas, misioneros y colonos desde el siglo XVII. Los españoles perseveraron en las misiones religiosas con los jesuitas y los franciscanos. Por su lado, los franceses insistieron hasta el último momento en la región de Cayena. En general, las estrategias para poblar la región hasta principios del siglo XVIII fueron limitadas. Arturo Cezar señaló que "los ingleses y los holandeses no poblaron bien. Sus colonias de Surinam, Demerara, Ezequibo, Berbice, no pasaron de ser factorías comerciales" (Reis, 1966).

Quizás, pero fue, sin duda, en la Amazonia donde más intensamente y de forma más original, las poblaciones indígenas gestaron una rica tradición de protesta y de reconfiguración étnica a través de la formación de comunidades de fugitivos.

Incluso considerando la inmensidad de esta área, lo poco poblado y la dispersión de las villas y poblados, los indígenas no se quedaron totalmente aislados. Hubo un movimiento de fugas y "mocambos de indios", especialmente a partir de 1760. Debido a los descimentos y a la desorganización de los Directorios, las fugas en masa de los indios de las reducciones fueron constantes. En la documentación este movimiento colectivo de fugas aparece como "mocambos de indios". También existen documentos indicando la formación de mocambos de africanos y de indios y las relaciones de éstos con los poblados en las fronteras. En la Amazonia, éste fue un proceso original de etno-génesis. Contó todo el tiempo con la lujosa ayuda de las micro-sociedades indígenas y de los vendedores itinerantes. Allí, las poblaciones indígenas, las poblaciones africanas y los colonos europeos -sin necesariamente el poder y el dominio colonial- traspasaron fronteras. Cruzaron también un mundo atlántico, esta vez navegando ríos que más parecían un mar, atravesando selvas y cataratas semejantes a murallas. Ensancharon sus propias fronteras cosmológicas y se reconstruyeron a sí mismos.

\section{Bibliografía}

\section{Fuentes documentales}

Carta del Gobernador de Pará, 14/06/1754. En Mendonça, M. C. (1967). A Amazônia na Era Pombalina, correspondência inédita do Governador e CapitãoGeneral do Estado do Grão-Pará e Maranhão, Francisco Xavier de Mendonça Furtado (1751-1759). Tomo 2. Rio de Janeiro: IHGB.

\footnotetext{
${ }^{10}$ APEPA, Códice 153 (1775). Ofício del Director de Benfica Antônio Gonçalves Ledo, 31/01/1775.

11 APEPA, Códice 192 (1781), Ofício de Joaquim Manoel de Meira e Melo enviado al Gobernador, 26/10/1781 y Códice 227 (1785), Ofício de 25/05/1785.
} 
Archivo APEPA

Códice 07 (1752-1769), Oficio de João de Morais, 19/05/1761.

Códice 07 (1752-1769), Oficio de João de Morais Bitencourt, 21/01/1764.

Códice 08 (1752-1773), Ofício de José Fernando Neves enviado a Manoel de Souza Coelho, 09/07/1752.

Códice 08 (1752-1773), Oficio de Manoel de Souza Coelho, 11/07/1752.

Códice 09 (1772-1777), Oficio de Manoel Antônio da Costa Sotto-Maior, 24/08/1773.

Códice 09 (1752-1777), Oficio del 16/11/1753.

Códice 12 (1759), Oficio del 01/07/1759.

Códice 14 (1759-1762), Oficio del 19/10/1761.

Códice 26 (1762), Oficio del 24/11/1762.

Códice 24 (1762), Oficio del 07/01/1762.

Códice 24 (1762), Oficio de Belchior Henrique, 04/02/1762.

Códice 24 (1762), Ofício de Belchior Henrique enviado al Gobernador, 01/03/1762.

Códice 25 (1762), Ofício de 10/05/1762.

Códice 26 (1762), Ofício de 24/11/1762.

Códice 27 (1762), Ofício de André Corsino Monteiro, 23/07/1762.

Códice 59 (1765), Oficio de João Francisco Furtado de Mendonça, 01/01/1765 y Oficio de Manoel Lobo de Almeida, 12/01/1765.

Códice 61 (1765), Ofícios de Nuno da Cunha de Ataíde Verona enviados al Gobernador, 03 y 23/08/1765.

Códice 93 (1769), Ofício de Joel Caetano Ferreira da Silva enviado al Gobernador Fernando da Costa Ataíde Freire, 20/08/1769.

Códice 96 (1769), Oficio de Antônio Albino Machado enviado al Gobierno de Pará, 17/06/1769.

Códice 97, Oficio de Belchior Henrique enviado al Gobierno de Pará, 18/10/1769.

Códice 103 (1770), Ofício de José Manoel Machado al Gobernador, 08/01/1770. 
Códice 112 (1770-1775), Ofícios de Florentino da Silveira Frade enviado al Gobernador João Pereira Caldas, 11 y 27/02/1775.

Códice 124 (1772), Ofício de Manoel de Gusmão enviado al Gobernador, 21/06/1772.

Códice 140 (1774), Ofícios de Joaquim de Mello e Povoa enviados al Gobernador João Pereira Caldas, 04/05 y 28/09/1774.

Códice 143 (1774), Ofício de Manoel da Gama Lobo de Almeida enviado al Gobernador João Pereira Caldas, 01/10/1774.

Códice 144 (1774), Oficios de Antônio Gonçalves de Souza, Director del Pesquero Real enviado al Gobierno de Pará, 16 y 17/04/1774.

Códice 146 (1774), Ofício de Francisco Luiz Ameno, 22/01/1774.

Códice 146 (1774), Ofício de Antônio José Pinto enviado al Gobernador João Pereira Caldas, 24/01/1774.

Códice 150 (1774-1780), Oficio de 22/03/1774.

Códice 151 (1775), Ofício del Director de Baião João Marçal enviado al Gobierno de Pará, 23/10/1775.

Códice 151 (1775), Ofício de Boaventura da Cunha Caldeira, Director de Fragoso, enviado al Gobernador João Pereira Caldas, 24/09/1775.

Códice 151 (1775), Oficio de Manoel Marques Mello enviado al Gobierno de Pará, 24/10/1775.

Códice 151 (1775), Oficio de José de Souza Morais enviado al Gobierno de Pará, 09/11/1775 y Oficio de Domingos Gonçalves, Director de Pinhel, 08/11/1775.

Códice 153 (1775), Ofício del Director de Benfica Antônio Gonçalves Ledo, $31 / 01 / 1775$.

Códice 153 (1775), Ofício de Antônio Gonçalves Ledo, 31/01/1775.

Códice 153 (1775). Ofício del Director de Benfica Antônio Gonçalves Ledo, $31 / 01 / 1775$.

Códice 165, Ofício de João Amorim Pereira enviado al Gobernador Fernando da Costa de Atayde Freire, 26/12/1766.

Códice 190 (1782), Ofício de 19/06/1782. 
Códice 192 (1781), Ofício de Joaquim Manoel de Meira e Melo enviado al Gobernador, 26/10/1781 y Códice 227 (1785), Ofício de 25/05/1785.

Códice 200 (1780), Oficio de Libório Souza enviado al Gobierno de Pará, 16/09/1780.

Códice 200 (1780), Oficio de 10/02/1780.

Códice 244 (1787), Ofício de Luiz da Rocha Lima al Gobierno de Pará, 28/11/1787.

Códice 246 (1787-1793), Ofício de Hilário de Moraes Bitancourt enviado al Gobernador Martinho de Souza Albuquerque, 01/09/1789.

Códice 262 (1790-1799), Ofício de João Garcia Galvão de Maio Farinha enviado al Gobierno, 02/04/1797.

Códice 279 (1793-1799), Ofício de Manoel Joaquim de Abreu enviado al Gobernador Don Francisco de Souza Coutinho, 29/07/1792.

Códice 290 (1795-1796), Ofício de Florentino da Silveira Frade enviado a Don Francisco de Souza Coutinho, 29/09/1795.

Códice 311 (1799-1800), Ofício de Luiz Pinto Cerqueira enviado al Gobernador D. Francisco de Souza Coutinho, 20/11/1799.

Códice 322, Ofício del Consejo de Ultramar enviado al Gobernador João Pereira Caldas, 15/10/1778.

Códice 324, Ofício de Joaquim Manoel Pereira Pinto enviado al Gobernador Don Francisco de Souza Coutinho, 09/08/1801.

Códice 339, Ofício de João Bernardes Borralho enviado al Conde de Arcos, 29/01/1805.

Códice 343, Oficio del Gobernador João Pereira Caldas enviado al Director de Vila de Borba Teniente Francisco Borges dos Santos, 26/02/1778.

Códice 356, Oficio de José Nápoles enviado al Gobierno de Pará, 05/01/1781.

Códice 356, Oficio de 22/06/1781.

Códice 456, Oficio de 18/01/1790.

Códice 466, Ofício del Gobernador Don Francisco de Souza Coutinho enviado al Capitán Narcizo Maciel Parente, 14/09/1790. 
Códice 549, Ofício de 09/06/1797; Ofício de 29/01/1799 y Ofício de 03/09/1799.

Códice 551, Oficio de 08/08/1798.

Códice 552 (1798), Ofício enviado al Gobernador D. Rodrigo de Souza Coutinho, 29/03/1798.

Códice 552, Oficio de 20/04/1798.

Códice 554, Ofício del Gobernador Don Francisco de Souza Coutinho enviado al Capitán Comandante de Santarém, 03/12/1799.

Códice 589 (1751-1773), Ofício enviado al Gobernador João Pereira Caldas, 26/05/1771.

Códice 606, Oficio de 18/08/1803.

Códice 614 (1795-1797), Ofício del Gobernador D. Francisco de Souza Coutinho enviado al Alferez Joaquim José Máximo, 12/06/1797.

\section{Fuentes bibliográficas}

Alden, D. (abril-jun 1985). El Indio Desechable en El Estado de Maranhão durante los siglos XVII y XVIII. América Indígena, XLV, 2.

Almeida, M. R. C. (sep-dic 1988). Trabalho Compulsório na Amazônia: séculos XVII-XVIII (112-114). Revista Arrabaldes. Año I, 2.

Azevedo, J. L. d'. (1901). Os Jesuítas no Grão-Pará, suas missões e colonização. Borguejo histórico com vários documentos inéditos. Lisboa: Edit. Tavares Cardoso \& Irmãos.

Belloto, H. L. (1988). Política Indigenista no Brasil Colonial (1570-1757) (55-56). Revista do Instituto de Estudos Brasileiros, 29. 1988.

Boxer, C. R. (1963). A Idade de Ouro do Brasil. São Paulo: Cia Edt. Nacional.

Coelho, M. C. (2007). A construção de uma lei: o Diretório dos Índios (29-48). Revista do Instituto Histórico e Geográfico Brasileiro, v. 168.

Craton, M. (1986). From Caribs to Black Caribs: The Amerindiam Roots of Serville Resistance in the Cariblean. En Okihiro, G. Y. (Ed.). Resistance Studies in African Caribbean, and Afro-American History. USA: The University of Massachusets Press, Ambrest,

Dreyfus, S. (1993). Os empreendimentos Coloniais e os Espaços Políticos indígenas no Interior da Guiana Ocidental (entre o Arenoco e o Corentino) de 1613 a 1796. En Castro, E. V. de \& Cunha, M. C. da. Amazônia: Etnologia e história indígena. São Paulo: NHII/USP, FAPESP. 
Farage, N. (1991). As Muralhas dos Sertões: os povos indígenas no Rio Branco e a colonização. Rio de Janeiro (31-33). Paz e Terra.

Farage, N. \& Amoroso, M. R. (orgs.) (1994). Relatos da Fronteira Amazônica no Século XVIII. Documentos de Henrique João Wilckens e Alexandre Rodrigues Ferreira. São Paulo: NHII/USP, FAPESP.

Hemming, J. (1978). Red Gold. The Conquest of the Brazilian Indians. USA: Harvard University Press, 1978

Hemming, J. (1987). Amazon Frontier. The Defeat of the Brazilian Indians, Londrés: MacMillan London.

MacLachlan, C. (1972). The Indian Directorate: Forced Acculturation in Portuguese América (1757-1799). The Americas, XXVIII, 4.

MacLachlan, C. M. (1973). The Indian Labor Structure in the Portuguese Amazon, 1700-1800. En Alden, D. (ed). Colonial Roots of Modern Brazil. USA: Papers of the Newberry Library Conference. Unuversity of Califórnia Press.

Menéndez, M. (1982). Uma contribuição para a Etno-História da área TapajósMadeira. Revista do Museu Paulista, São Paulo, XXVIIII.

Monteiro, J. M. (1994). O escravo índio, esse desconhecido. En Grupioni, L.(Org.) Indios no Brasil. Brasília: MEC.

Moreira Neto, C. de A. (1988). Índios da Amazônia, de maioria e minoria (1750-1850). Petrópolis: Ed. Vozes.

Perrone-Moisés, B. (1991). Índios Livres e Índios escravos. Os princípios da legislação do período colonial (séculos XVI a XVIII). En: Carneiro da Cunha, M. (org.). História dos Índios no Brasil. São Paulo: Cia. Das Letras.

Porro, A. (1983-1984). Os Solimões ou Jurimaguas. Território, Migrações e Comércio Intertribal. Revista do Museu Paulista, XX/XXI.

Queiroz, Fr. J. S. J. (1961). Visitas Pastorais. Memórias (1761-1762). Rio de Janeiro: Ed. Melso.

Salles, V. (1971). O Negro na Pará sob o regime da escravidão. Belém: FGV.

Sampaio, P. M. M. (2007). Vossa mercê mandará o que for servido...: políticas indígenas e indigenistas na Amazônia Portuguesa, século XVIIII (39-55). Tempo. Revista do Departamento de História da UFF, v. 12.

Sweet, D. G. (1974). A Rich Realm of Nature Destroyed: The Middle Amazon Valley, 1640-1750. Wisconsin: Tesis Ph.D The University of Wisconsin. 
Sweet, D. G. (jun-dic 1978). Black Robes and 'Black Destiny': Jesuit Views of African Slavery in 17 th Century Latin América. Revista de História de América, México, 86.

Servlnikov, S. (mayo 1996). Disputed Imagens of Colonialism: Spanish Rule and Indian Subversion in Northern Potosí, 1777-1780. Hispanic America Historical Review, 76, 2.

Reis, A. C. F. (1966). Aspectos da Experiência Portuguesa na Amazônia. Manaus: Governo do Estado, 1966, pp. 135.

Recibido: 25 de marzo de 2010. Aprobado: 11 de mayo de 2010 